Antithyroid drugs may be defined as chemical agents which interfere with the synthesis, release or peripheral action of the thyroid hormone. A large number of chemically unrelated compounds are covered by this definition, but it is intended to deal only with those which have a place in the practical management of hyperthyroidism. Such drugs can be divided into three categories:

(I) Drugs preventing the synthesis of organic iodine from inorganic iodide.

(2) Drugs inhibiting the iodide trap of the thyroid.

(3) The iodide ion.

Thiourea, the parent compound of most of the antithyroid drugs of the first group which are used therapeutically, was shown to be goitrogenic by Griesbach et al. (194I) and Kennedy (1942). The latter also showed that a derivative of thiourea was responsible for the goitrogenic properties of Brassica seeds. Astwood (1943) further confirmed the antithyroid activity of thiourea and its derivatives and in 1944 published the first clinical report on thiourea and thiouracil in the treatment of hyperthyroidism. The toxic effects of these drugs soon diminished the initial enthusiasm for antithyroid drug therapy, but this was revived by the introduction of 4-methyl thiouracil and 6 -N-propyl thiouracil, which because of their greater potency were effective in smaller doses and had fewer side effects. Both drugs had extensive clinical trials and are still widely used. Stanley and Astwood (1949) then demonstrated that I - methyl - 2 - mercaptoimidazole (methimazole, 'Mercazole,' ' Tapazole ') had greater antithyroid activity than any other known compound, while Bartels and Sjogren reported a successful clinical trial of the drug in 1951. Methimazole is widely used in the United States, but in this country 2 - carbethoxythio - I - methyl - glyoxaline (carbimazole, 'Neomercazole ') synthesized by Rimington and his associates (1951), is the more popular of the imidazole derivatives.

The history of drugs inhibiting the iodide trap of the thyroid began with the demonstration by Marine and his associates (1932) that acetonitrile and related compounds could produce thyroid hyperplasia and that the effect was antagonized by iodine., In 1953, Wyngaarden et al., studied the antithyroid activity of various anions and con- cluded that the perchlorate ion was the most potent inhibitor of the iodide-trapping mechanism of the thyroid. This was followed in 1954 byes successful clinical trials of potassium perchlorate $\overrightarrow{0}$ in hyperthyroidism (Godley and Stanbury, 1954 Morgans and Trotter, 1954).

Iodide is the oldest of the antithyroid drugs andoㅇ was the only one available for clinical use up to 1943. Although it had been occasionally used in hyperthyroidism during the early part of the 20 thw century, its use only became popular followingo Plummer's report of a successful clinical trial in 1923 .

Group I: Drugs Preventing the Iodination of Tyrosine

The antithyroid drugs to be discussed in this group are methyl thiouracil, propyl thiouracil, $\vec{\theta}$ methimazole and carbimazole.

\section{Mechanism of Action}

While the exact mechanism of action of the drugs is controversial, there is general agreemento that they interfere with the iodination of theo thyroid hormone precursors without affecting the $\stackrel{\mathbb{Q}}{\circ}$ ability of the gland to concentrate the iodide ion. $\overrightarrow{\vec{O}}$ The three current hypotheses given to explain this 3 action are:

(I) They may inhibit the enzyme systems which oxidize ionic to elemental iodine.

(2) They may compete with iodide as a sub- 3 strate for this oxidative enzyme.

(3) Elemental iodine may be reduced to the iodide ion depriving the thyroid cell of iodineo necessary for synthesis of the thyroid hormone. $₹$

Whatever the exact machanism of action, the을 level of circulating hormone falls, leading to in- $>$ creased production of thyrotropic hormone by을. the pituitary with consequent thyroid hyperplasia. No

\section{Structure-Activity Relationships}

กิ

The antithyroid activity of these drugs has been ${ }_{\mathrm{E}}$ studied using radioiodine techniques (Stanley ando Astwood, 1947; Macgregor and Miller, 1953) and their potencies relative to thiouracil are shown $\frac{\mathbb{\Phi}}{\varnothing}$ in parentheses below:

Thiouracil (1), Methyl thiouracil (2), Propyl thiouracil (0.75), Methimazole (I00), Carbimazole 0 (100). 


\section{Indications for Use}

In recent years the indications for the use of these drugs in hyperthyroidism have become more clearly defined. Most authorities agree that young adults with small or moderately enlarged, diffuse goitres should be given a prolonged trial of antithyroid drugs. When the disease occurs during pregnancy or puberty this form of therapy allows more flexible control of thyroid function during a period when the metabolic demands on the thyroid are varying. Before partial thyroidectomy is carried out toxicity should be controlled by treatment with one of these drugs. In some thyrocardiac subjects where rapid control of toxicity is required a short course of one of the drugs of this group can begin ten days after radioiodine therapy. Finally, in patients where the diagnosis of thyrotoxicosis remains in doubt after full investigation, the patient's reponse to antithyroid drug therapy should be observed.

\section{Dosage}

A large number of dosage schemes have been used. For example, Iversen (I95I) gave $750 \mathrm{mg}$. methyl thiouracil daily for one to three months. reducing the amount until a dose of $125 \mathrm{mg}$. was given daily on alternate days. On the other hand Himsworth (1948), in an attempt to avoid myxoedema, used an initial daily dose of $200 \mathrm{mg}$. methyl thiouracil with maintenance doses of 25 to roo mg. The scheme of dosage for methyl thiouracil used in this department, $600 \mathrm{mg}$. daily for two weeks, then $300 \mathrm{mg}$. daily until the patient is euthyroid, followed by a maintenance dose of 50 to roo mg. daily, has been found to be entirely satisfactory.

In the case of propyl thiouracil approximately the same dosage scheme may be used as for methyl thiouracil, though many workers have tended to use slightly lower doses.

The variation in schemes of dosage has persisted with the newer drugs of this group, methimazole and carbimazole. For both substances initial doses of 20 to $40 \mathrm{mg}$. daily followed by maintenance doses of 5 to $15 \mathrm{mg}$. daily usually produce satisfactory results, though in some cases a larger initial dose is necessary.

In arriving at the optimum dose, a balance has to be struck between the rate of control of symptoms and the incidence of toxic effects, the higher the dose the more rapid being the rate of control and the higher the incidence of toxic effects.

\section{Response to Treatment}

(I) Rate of Control. The therapeutic response to treatment as measured by the disappearance of the symptoms and most of the signs of hyperthyroidism is uniformly satisfactory, and the majority of cases treated with methyl thiouracil in this department become euthyroid in four to ten weeks. The rate of control of the disease would appear to be related to the dose of each drug and not to the drug itself, for example, $30 \mathrm{mg}$. of methimazole daily appears to control hyperthyrodism more rapidly than $300 \mathrm{mg}$. methyl thiouracil daily, but no more rapidly than $600 \mathrm{mg}$. methyl thiouracil daily. Other factors can influence the rate of control, for example, patients with nodular glands tend to respond slowly, though ultimate control is satisfactory. In cases responding unexpectedly slowly or incompletely the cause is usually found to be one of the following:

(i) Failure of the patient to take the prescribed tablets or to space the doses properly.

(ii) A course of iodine has preceded the antithyroid drug.

(iii) A larger dose of the drug is required.

(iv) The diagnosis of hyperthyroidism is wrong.

(2) Changes in Clinical Features. The most persistant symptom is heat intolerance, while the last physical sign to disappear, excluding the goitre and the eye signs, is the tachycardia. When auricular fibrillation is present before treatment reversion to sinus rhythm is obtained in aboug one-third of cases within four months, but some of those continue to have paroxysms of fibrillation although euthyroid. Failure and partial success in? such cases is doubtless due to coincident coronary artery disease. Weight increase tends to lag behind the disappearance of most of the other features. The goitre in most cases is unchanged at first, but occasionally may increase slightly. The bruit too persists. During maintenance therapy the gland size usually remains unchanged. However, in some cases it diminishes markedly and this is associated with a greater possibility of permanent remission. In this department regular exophthalmometry readings have shown, in 15 per cent. of subjects, a significant increase in exophthalmos, which tends to regress when treatment is stopped. This compares favourably with the 75 per cent. increase after partial thyroidectomy reported by Soley (1942).

(3) Assessment of Response. The only satisfactory method of ascertaining response to treatment is by clinical assessment, changes in objective signs being particularly valuable. The basal metabolic rate, using Robertson and Reid's standards, usually falls within the normal range one to three weeks before the patient is clinically euthyroid. The serum cholesterol tends to rise rapidly after two to three weeks of treatment, but is not of value in deciding when the patient is euthyroid. 


\section{Duration of Treatment, Remissions and Relapses}

Those authorities who advocate long periods of continuous antithyroid drug therapy have theoretical support for their view in that these drugs are unlikely to shorten the course of the disease and that when prolonged remissions are obtained the disease has spontaneously run its course. Iversen (195 I) for example, believes that treatment should be carried on for six months or longer, while Dunlop and Rolland (1950) found a relapse rate of 69 per cent. after treatment of under one year, compared with 33 per cent. over one year. On the other hand, Bartels (1950) and Goodwin et al. (1954) maintain that the duration of treatment bears no relation to the length of the subsequent period of remission. Eight of twenty patients treated here with methyl thiouracil and kept on a maintenance dose for three months only, relapsed within six months. Higher relapse rates have been found in cases with post-operative recurrences and nodular goitres (McCullagh et al., I95 I) and one of the reasons for the great variation of results obtained by different workers is likely to be found in the type of cases treated.

On the basis of the available evidence it would appear that at least a year's continuous therapy with an antithyroid drug is desirable except in patients with mild thyrotoxicosis and small diffuse goitre, who might be given shorter courses, particularly if there is a diminution in the size of the goitre during treatment.

\section{Pre-operative Treatment}

It is generally agreed that antithyroid drugs of this group should be used to prepare a thyrotoxic patient for partial thyroidectomy. Some authorities, however, believe that such pre-operative preparation is not always necessary and would confine it to severe cases (McCullagh and Surridge, 1948; Pemberton et al., 1949). However, there has been a definite decrease in operative mortality since the use of these drugs pre-operatively became general. In the two weeks preceding operation iodine in the form of potassium iodide $30 \mathrm{mg}$. daily should be substituted in order to diminish the vascularity of the gland.

\section{Treatment During Pregnancy}

Goitre and hypothyroidism have been reported to occur in the infants of mothers receiving antithyroid drug therapy (Eaton, 1945; Ball and Morrison, I948), but this is an uncommon event. Astwood (195I) points out that if the dose of the antithyroid drug has been adjusted to ensure a normal output of hormone by the maternal thyroid it is unlikely that the function of the foetal gland would be significantly depressed. $\mathrm{He}$ reported 22 completed pregnancies in 19 patients, the 22 living children showing no evidence of thyro: disturbances. In most instances where a goitice has been reported in an infant there is evidence overdosage and it is the practice in this departmeat to under-treat pregnant subjects since pregnancy itself is a hypermetabolic state. In three cas treated in this way during the past year, none of the children had a goitre. The infants in suçe cases should not be breast fed in order to avoid the transmission of the antithyroid drug in the mils.

The importance of the flexible control of thyro toxicosis in pregnancy made possible by the use of antithyroid drugs is underlined by the higt incidence of miscarriages and stillbirths untreated cases.

\section{Complications of Treatment}

The first two drugs used, thiourea and thiouracin were extremely toxic and no drug of this group has proved to be totally free from side-effects. The more recently introduced compounds are, however, relatively safe therapeutic agents.

There is a group of toxic effects which are ve uncommon and which include nausea, vomiting, diarrhoea, jaundice and headache. Only the major toxic effects will be considered in detail and they can be conveniently divided into sensitivity reactions and depression of bone marrow elemegt

\section{Sensitivity Reactions}

A skin rash is the most common manifest 으음 and is usually urticarial although a variety of othgr types of rashes do occur. Another commogit sensitivity reaction is drug fever. Much les commonly lymph and salivary gland enlargement, arthralgia and conjunctivitis have been reporte\&. These reactions tend to occur between the tenth and eighteenth days of treatment or within the first 14 days after treatment has been resumed. The reactions usually last two to three days and the skin rashes generally respond to treatment with an antihistaminic drug such as promethazine hydrä. chloride. The less severe reactions of this type 80 not require the cessation of therapy, but since the incidence of subsequent bone-marrow depression is increased in such cases, it is probably advisable to change to an alternative therapeutic agent, sue as potassium perchlorate. There would seem be little to choose between methyl thiourac@i prophyl thiouracil and methimazole with respegt to the incidence of those reactions but with carbimazole the incidence would appear to be less (Burrell et al., 1956).

\section{Agranulocytosis}

This is the only potentially lethal complication of treatment with this group of drugs. The agranulocytosis may be of two types, the cord - 
moner being impairment of white cell maturation at the pre-myelocyte or myelocyte level and, since the availability of penicillin, carrying a good prognosis. The other, and graver type where the maturation defect is at myeloblast level, can be differentiated by a marrow biopsy which should always be carried out in cases suspected of agranulocytosis. There seems to be little doubt that thiouracil produced this complication more often than any of the others and Moore (1946) found an incidence of 2 per cent. in 9,281 cases.

Reviewing the results of other workers using methyl thiouracil, Barfred (1947) found that 9 of 604 cases developed agranulocytosis, an incidence of 1.49 per cent. Bartels (1948) reporting 486 cases treated with propyl thiouracil found two cases of agranulocytosis ( 0.4 per cent.), but the initial dosage used for propyl thiouracil had a less potent antithyroid action than methyl thiouracil and it is likely that the toxicity of the two drugs are comparable. Using methimazole, Bartels and Sjogren (195I) had one case of severe granulocytopenia in 100 treated cases, and Doniach (1953) using carbimazole in 120 patients found no toxic effects and attributed this to a more gradual release by hydrolysis of the active ' thiol' group which it has in common with methimazole. In this last series it is of interest that three patients who had had toxic effects with methyl thiouracil had no complications on carbimazole. Burrell et al. (1956) concluded that carbimazole was the least toxic of this group of drugs in a survey of I,046 patients and a review of the literature, but eight cases of agranulocytosis have already been reported in the United States and this country during the use of this drug.

In the practical management of the patient most authorities now agree that there is little yalue in carrying out serial white blood counts at weekly or longer intervals because agranulocytosis can occur so rapidly. Close, but not obsessive watch should be kept over the patient under treatment, especially during the first eight weeks, when the incidence of toxic effects is highest.

\section{Group II: Drugs Inhibiting the Iodide Trap of the Thyroid}

The anions which possess a significant goitrogenic, action are, in order of decreasing activity, perchlorate, thiocyanate and nitrate. Thiocyanate and nitrate have no therapeutic importance as antithyroid drugs because of their toxicity. Potassium perchlorate has, however, been used successfully in the treatment of thyrotoxicosis and much of the description which follows is based on personal experience in over 50 cases treated during the past 18 months.

\section{Mechanism of Action}

The goitrogenic action of these anions can be overcome by the administration of iodide and this suggests they interfere with the uptake of inorganic iodide by the thyroid (Franklin et al., 1944; Wyngaarden et al., 1953). Furthermore, inorganic iodide already trapped by the thyroid is discharged by the administration of the anions. The exact mechanism by which the anions act is unknown, but presumably if the circulating blood iodide level is high enough, the block can be overcome.

\section{Potassium Perchlorate in the Treatment of Thyrotoxicosis}

The therapeutic value of perchlorate as an antithyroid drug has not been fully evaluated. Weight for weight it is a less potent agent than methyl thiouracil and using a dose of $200 \mathrm{mg}$. three times daily the rate of control is more variable than with methyl thiouracil, the euthyroid state being achieved in from 7 to 20 weeks. Some patients prove resistant to the drug, but in all but one of $5^{2}$ cases adequate control was finally achieved. It is possible that larger doses should be used and our present dosage scheme is $200 \mathrm{mg}$. five times daily. Patients are advised to avoid eating fish, taking cough mixtures and othero medicines containing iodine, and to use uniodised salt. The clinical response to treatment, apartêfrom the rate of control, is similar to that produced. by methyl thiouracil.

As might be expected from the relatively simple perchlorate molecule, the drug is the least toxic of the antithyroid drugs with therapeutic applications. Of the 52 cases only one complained of dyspepsia while taking the drug and this disappeared although therapy was continued. Godley and Stanbury (1954) reported one case of dyspepsia and one case in whom a duodenal ulcer perforated, in a series of 24 patients treated with perchlorate. Morgans and Trotter (1954) treated 108 cases with this drug and the only side effects observed were gastro-intestinal symptoms in two patients, one of whom had a diaphragmatic hernia and the other a peptic ulcer. There is no evidence that perchlorate causes hypersensitivity reactions, or has any depressant effect on the bone marrow. It is, therefore, a valuable alternative in cases who have had toxic effects caused by the drugs of Group I.

Potassium perchlorate is probably unsuitable for the treatment of patients preceding partial thyroidectomy since Godley and Stanbury (1954) found that the glands were more vascular than would be expected with thiourea derivatives and iedide. The effect of perchlorate in the pregnant thyrotoxic subject has not so far been reported, but 
in one case treated here, the infant showed no thyroid abnormality at birth.

\section{Group III: The Iodide Ion}

It is intended to discuss iodothiouracil along with the iodide ion, as they behave similarly.

\section{Mechanism of Action}

The iodide ion when given in therapeutic doses results in involution of the gland and an increase in colloid storage even in the presence of a goitrogen. It also leads to a reduction in the release of thyroid hormone (Ansell and Miller, 1952). However, suppression of thyroxine synthesis and release would appear to be evanescent (Wolff et al., 1949). It is not clear whether iodide acts directly on the thyroid or by the inhibition of the pituitary secretion of thyrotropic hormone.

\section{Iodide and Iodothiouracil in the Treatment of Thyrotoxicosis}

The symptomatic response of thyrotoxicosis to the administration of iodide as potassium iodide or Lugol's iodine, is rapid and has been used as a therapeutic test. The maximum effect is obtained in Io to 15 days but following this escape from control is common and there may even be an exacerbation of symptoms. It is mainly used in the preparation of patients for partial thyroidectomy and it should be given for two weeks before operation either with or following one of the drugs of Group I. When rapid control of toxicity is required after radioiodine therapy a course of iodide lasting three weeks can be started ten days after the radioiodine has been given.

Opinions are divided concerning the place of 5-iodo-2-thiouracil (iodothiouracil) in therapy, but Williams et al. (1949) came to the conclusion that the response to this drug was more like that observed with iodide than with thiouracil. The recommended initial dose of $150 \mathrm{mg}$. daily only contains $75 \mathrm{mg}$. of thiouracil. It is favoured by some surgeons for pre-operative preparation, but like iodide, has no place in the long-term treatment of hyperthyroidism.

\section{Drugs having an Antithyroid Action as a Side-effect \\ A number of drugs with therapeutic applications in other fields have also an antithyroid action. Important examples of such goitrogens are para- aminosalicylic acid (Macgregor and Somner, 1954), resorcinol (Bull and Fraser, 195I), and cobalt (Kriss et al., 1955).}

\section{The Advantages and Disadvantages of Antithyroid Drugs}

The most important advantage possessed by these drugs in the treatment of thyrotoxicosis, is the flexibility of control of thyroid function which can be achieved by careful prescribing. This is $\mathscr{\Theta f}$ particular value in those states where the metabol demands on the thyroid are fluctuating, fö example, in pregnancy and at puberty. This room for therapeutic manoeuvre is also of value cases with marked exophthalmos where exacerb tion following surgery may be feared and whese the indications for radioiodine therapy may not fulfilled. The absence of the risk of permanent myxoedema is another advantage not shared 10 surgery and radioiodine therapy. That this form of treatment can be given without admission $\vec{t}$ hospital may be of considerable economic ad: vantage to the patient and its general availabilify is of special value in areas where there is skilled thyroid surgeon or centre equipped carry out radioiodine therapy.

The main disadvantage of these drugs is the lorfe duration of therapy. Adequate and safe contrŏ can, however, be achieved by clinical assessme $\overrightarrow{t t}$ alone, fairly frequently in the first two month and at much longer intervals subsequentl $\Phi$. However, even if this is done and the inconvenience of long term therapy minimised, the personality of some patients makes them unsuitab庵 for this form of treatment. With the introduction of carbimazole and perchlorate, the hazards of therapy are comparable to that of the best surgery and certainly less than that of inferior surgert. The overall relapse rate of $5^{\circ}$ per cent. even aft long term therapy with antithyroid drugs has beem a great disappointment, especially since trine possibility of permanent remission cannot predicted before treatment is begun.

In conclusion, the effective use of antithyroid drugs demands the selection of suitable patients. careful clinical assessment of progress and a a justment of dosage, and above all, patience.

\section{Acknowledgement}

I wish to thank Professor E. J. Wayne fö helpful criticism and advice regarding the preparation of this paper.

\section{BIBLIOGRAPHY}

ANSELL, G., and MILLER, H. (1952), Lancet, ii, 5. ASTWOOD, E. B. (1943), भ. Pharmacol., 78, 79.

ASTWOOD, E. B. (1944), Ұ. clin. Endocr., 4, 229.

ASTWOOD, E. B. (195I), Ibid., I1, 1045.

BALL, K. P., and MORRISON, B. (1948), Proc. roy. Soc. Med.,

BARFRED, A. (1947), Amer. F. med. Sci., 214, 349.

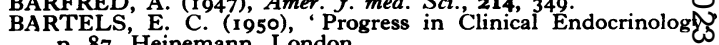
p. 87, Heinemann, London.

BARTELS, E. C. (1948), Ұ clin. Endocr., 8, 766. BULL, G. M., and FRASER, R. (I95I), Lancet, i, 851. II, Co Brit. med. $\mathcal{F}$, i, 1453 .

DONIACH, D. (1953), Lancet, i, 873

DUNLOP, D. M., and ROLLAND, C. F. (1950), Proc. roy. S

EATON,'J. C. (1945), Lancet, i, I 71 .

Continued on page 332 
that liver changes usually accompanied the condition (Cooke and Luxton, 1955) and a larger confirmatory series appeared from the Cleveland Clinic (Skillern, 1956) last year. The raised $\gamma$ globulin levels, their delayed return to normal after thyroidectomy and the infiltration of the thyroid with lymphocytes, plasma cells and lymphoid tissue prompted Roitt et al. (1956) to look for an immune response. They have reported a precipitin reaction of serum with extract of human thyroid gland and they postulate that it parallels the destruction of the patient's own thyroid, and especially the colloid, by an auto-antibody.

It might well be expected that in subacute thyroiditis a similar positive flocculation test would be obtained and W. R. Trotter and D. Doniach inform me that they have obtained a positive reaction in the serum of two patients with this disease.

For those who are interested in recent advances in problems of immunology and thyroid disease there is an excellent leading article in the Lancet, May 25, 1957, Vol. I, p. I075, which reviews the whole subject up to the present time. This has now become one of the rapidly expanding frontiers of thyroid investigation.

\section{Acknowledgment}

We are indebted to the publishers of British
Surgical Progress 1955 for the blocks which apped in this article.

\section{BIBLIOGRAPHY}

CLARK, D. E., and NELSEN, T. S. (1953), four. Amer. med. Ass COOKE, 551 . T., and WILDER, E. (1954), Lancet, $i_{1} 984$. COOKE, R. T., and LUXTON, R. W. (1955), Ibid., 1, 968.

CRILE, G., Jr. (1948), Ann. Surg., 127, 640., Cancer, 6, 57. . 흘. CRILE, G., Jr., and HAZARD, J. B. (r951), $\}$. clin. Endock CRILE, G., Jr., and RUMSEY, E. W. (1950), f. Amer. med. As

DE QUUE, $45^{8}$. DE QUERVAIN, F., and GIORDANENGO, G. (1935), Ibid.. FRA ${ }^{4}{ }^{538}$.

HAMLIN, E., Jr., and VICKERY, A. L.'(1956), New Eng. Med., 214, 742.

HAZARD, J. B. (1955), Amer. F. clin. Path., 25, 399. HEPTINSTALL, R. H., and EASTCOTT, H. H. G. (195过

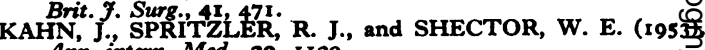
Ann. intern. Med., 39, II29, L. J. (1945), F. Amer. med. Ass. KING, B. T.

LASSER, R. P. (1953), Ibid., 152, 1133.

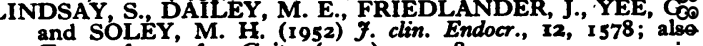
Trans. Amer. Ass. Goiter (1952), pp. 384-411.

LINDSAY, S., and DAILEY, M. E. (1954), Surg. Gynec. Obstent

PERLOÓFF, W. H. (1956), \%. clin. Endocr., 16, 542. R. W. (1951) Ibid. II, I IO6.

ROITT, I. M., DONIACH, D., CAMPBELL, P. N., and HUDSÓN, R. V. (1956) Lancet, it, 820 .

SKILLERN, P. G., CRILE, G., MCCULLAGH, P., HAZARF J. B., LEWIS, L. A., and BROOWN, H. (1956), भ. clin. Endocr. 16, 33. S. (1955), ' Brit. Surg. Progress,' pp. 148-160, Lorgofo

\section{RUTHIN CASTLE, NORTH WALES}

A Clinic for the diagnosis and treatment of Internal Diseases (except Mental or Infectious Diseases). The Clinic is provided with a staff of doctors, technicians and nurses.

The surroundings are beautiful. The climate is mild. There is central heating throughout. The annual rainfall is 30.5 inches, that is, less than the average for England.

The Fees are inclusive and vary according to the room occupied.

For particulars apply to THE SECRETARY, Ruthin Castle, North Wales.

Telegrams: Canke, Ruchin.

Telepheme: Ruchin 66

Bibliography continued from page 326-Fames Crooks, M.B., M.R.C.P.(Lond. and Ed.), F.R.F.P.S.G.

FRANKLIN, A. L., LERNER, S. R. and CHAIKOFF, I. L.,

GODLEY,, Andocrinology $34{ }^{265}$. F., and STANBU, J. B. (195)4, f. clin. Endocr. I4.70.

GOODWIN, J. F., STEINBERG, H., and WILSON, A. (1954),

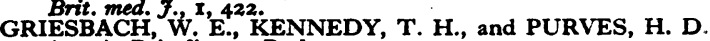
(1941), Brit. F. exp. Path., 22, 249.

HIMSWORTH, H. P. (1948), Brit. med. F., 2, 61

IVERSEN, K. (1951), $\mathcal{F}$. clin. Endocr., II, 298 .

KENNEDY, T. H. (1942), Nature (Lond.), 150, 233.

KRISS, J. P., CARNES, W. H., and GROSS, R. T. (1955),

LAWSON, A., RIMINGTON, C., and SEARLE, C. E. (r95r), Lancet, ii, 6r9.

MARINE, D., BAUMMANN, E. J., SPENCE, A. W., and CIPRA, A. (1932), Proc. Soc. exp. Biol. (N.Y.), 29, 772.

MOORE F. D. (1946), \&. Amer. med. Ass., 130, 315.

MORGANS, M. E., and TROTTER, W. R. (r954), Lancet, i, 749.
MCCULLAGH, E. P., HUMPHREY, D. C., MCGARVEY, C. and SUNDGREN, V. (1951), F. Amer. med. Ass., 147, 106. MCCULLAGH, E. P., and SURRIDGE, W. T. (1948), $\mathcal{F}$. cling MACGREG̈OR, A. G., and MILLER, H. (1953), Lancet, i, $88 \mathrm{I}$ MACGREGOR, A. G., and SOMNER, A. R. (1954), Ibid., ii, 93 PEMBERTON, J. J., HAINES, S. F., and KEATING, F. R (1949), Ұ. clin. Endocr., 9, 1232.

PLUMMER, H. S. (1923), Ұ. Amer. med. Ass., 80, 1955

SOLEY, M. H. (1942), Arch. intern. Med., 70, 206.

STAN'LEY, M. M., and ASTWOOD, E. B. (1949), Ibid., 44,58 WILLIAMS, R. H., TOWERY, B. T., ROGERS, W. F., TACA WOLFF, R., and JAFFE, H. (1949), Gं clin. Endocr., 9, 801. and

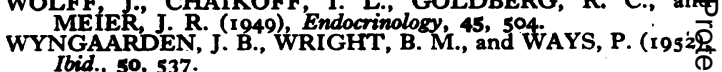
Ibid., 50, 537 . 